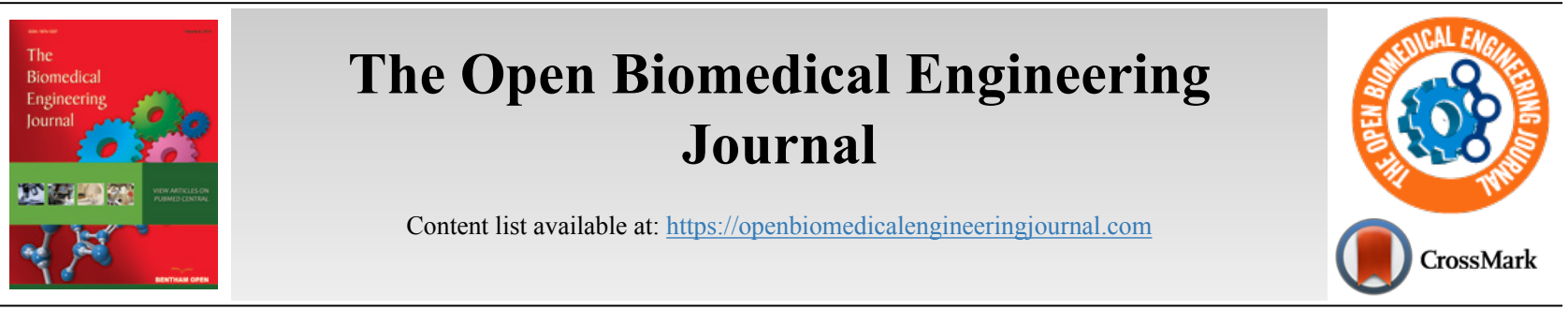

REVIEW ARTICLE

\title{
A Comprehensive Review on Wearable Health Monitoring Systems
}

\author{
Rahul K. Kher, ${ }^{1, *}$ and Dipak M. Patel ${ }^{2}$ \\ ${ }^{\prime}$ Electronics \& Communication Engineering, G. H. Patel College of Engineering \& Technology, Vallabh Vidyanagar, India \\ ${ }^{2}$ Department of Electronics Engineering, B. V. M. Engineering College, Vallabh Vidyanagar-388120, India
}

\begin{abstract}
:
This paper presents a comprehensive review of the wearable healthcare monitoring systems proposed by the researchers to date. One of the earliest wearable recorders, named "a silicon locket for ECG monitoring", was developed at the Indian Institute of Technology, Bombay, in 2003. Thus, the wearable health monitoring systems, started with the acquisition of a single signal/ parameter to the present generation smart and affordable multi-parameter recording/monitoring systems, have evolved manifolds in these two decades. Wearable systems have dramatically changed in terms of size, cost, functionality, and accuracy. The early-day wearable recorders were with limited functionalities against today's systems, e.g., Apple's iWatch which comprises abundant health monitoring features like heart rate monitoring, breathing app, accelerometers, smart walking/ activity monitoring, and alerts. Most of the present-day smartphones are not only capable of recording various health features like body temperature, heart rate, photoplethysmograph (PPG) signal, calory consumption, smart activity monitoring, stress measurement, etc. through different apps, but they also help the user to get monitored by a family physician via GSM or even internet of things (IoT). One of the latest, stateof-the-art real-time personal health monitoring systems, Wearable IoT-cloud-based health monitoring system (WISE), is a beautiful amalgamation of body area sensor network (BASN) and IoT framework for ubiquitous health monitoring. The future of wearable health monitoring systems will be far beyond the IoT and BASN.
\end{abstract}

Keywords: Wearable devices, Health monitoring, Wearable- ECG, Physiological parameters, IoT, BASN.

\begin{tabular}{l|l|l|r} 
Article History & Received: August 31, 2020 & Revised: January 7, 2021 & Accepted: July 2, 2021
\end{tabular}

\section{INTRODUCTION}

In this age of tough competition and stress, heart-related diseases and abnormalities are commonly being found in people even at an early age. To detect cardiovascular diseases (CVDs) earlier and treat them properly, people must do body check-ups regularly. This sometimes requires hospitalization. However, due to various constraints, it may not be possible for everyone to maintain consistency in this regard [1 - 5]. Using wearable devices (WD) is a convenient option for hospitalization. Nowadays, inexpensive WDs are available for health monitoring which are compact and light in weight. They are capable of measuring physical parameters like body temperature, heart rate, blood pressure, electrocardiogram (ECG), etc., for a very long time. One such useful device is a wearable ambulatory ECG recorder, commonly known as WECG or A-ECG recorder. They are capable of updating the doctor about the occurrence of any abnormal event to the wearer in addition to recording the ECG signals and related physiological parameters [6 - 14]. This is possible due to advancements in telemedicine.

\footnotetext{
* Address correspondence to this author at Department of Electronics \& Communication Engineering, G H Patel College of Engineering \& Technology, 26, Raghuvansh society, Nr Hariom nagar, Inidia; Tel: 9825018315;

E-mail: rahul2777@gmail.com
}

People nowadays are at risk of various heart disorders because of the type of lifestyle they are living and increased stress levels. The researchers have come up with tele-home-care solutions by using novel standards and wireless technologies in patient care and monitoring. The patient can remain in continuous touch with the physician due to wireless technology and wearable sensors. Stretchability and sensitivity are two important features in wearable sensors/devices/ systems. Conventional piezoelectric sensors are self-powered, but they lack stretchability. The kirigami stretchable piezoelectric sensor is one such sensor that exhibits stretchability and is used in cardiac monitoring and wearable body tracking applications. The integrated sensor demonstrates excellent in vitro and ex vivo performances and provides insights for the potential use in a myriad of biomedical and wearable health monitoring applications. Recently, metamaterial-based and soft, stretchable, and biocompatible sensors have been proposed, and they have shown promising results.

\section{MODERN WEARABLE HEALTH MONITORING SYSTEMS}

The modern wearable ECG recording and monitoring systems existing in the literature are described in this section. To record the A-ECG signals for a long time (for many hours 
and even for days), a compact, lightweight WD is used nowadays. V. Vaid et al. [1,2] developed one such WD at IIT Bombay, which is capable of recording a single-lead A-ECG. Its prototype model is shown in Fig. (1).

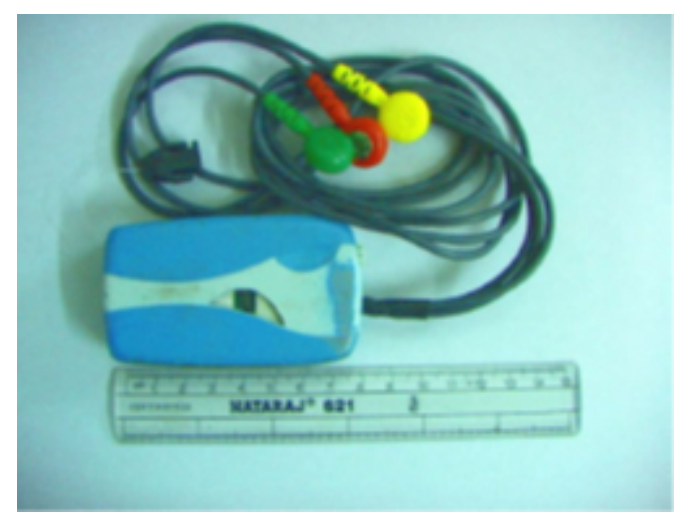

Fig. (1). Wearable ECG recorder developed by Lal et al. [2] Copyright CIEEE 2006

A wearable ECG recorder for daily stress measurement has been developed by Okada et al. [3], as shown in Fig. (2). The body is collapsible and made of plastic. It weighs just $45 \mathrm{~g}$ and includes a battery and a 1 GB memory card. Its width, depth, and height measurements are 44 x 17 x $58 \mathrm{~mm}$ respectively. An $\mathrm{R}$-wave detection is indicated by the red LED flashes. There are two switches (ON/OFF, START/STOP) and two lightemitting diodes (LEDs). The memory card and battery are easily replaceable. The device also contains three in-built accelerometer sensors.

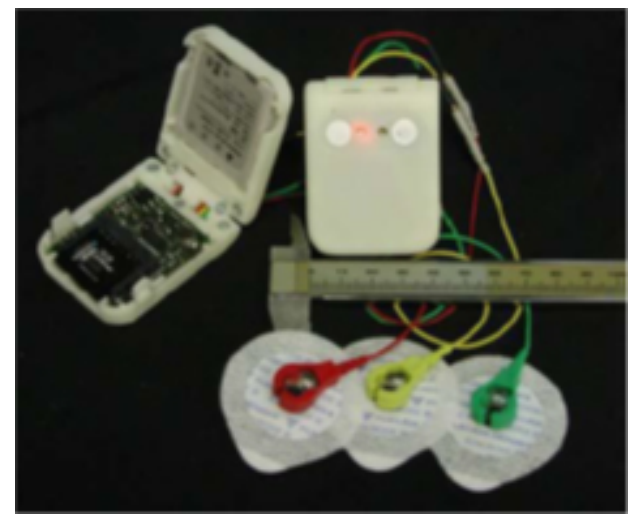

Fig. (2). Portable ECG recorder developed by Okada [3] Copyright $($ ) IEEE 2010

Park, Bai et al. [4] have developed an ultra-low-power, wearable ECG monitoring system using QUASAR's innovative ECG sensor and an ultra-compact wireless sensor node shown in Fig. (3). They have used 1 Mbps proprietary radio, a very low power transceiver, in place of IEEE 802.15.4. This transceiver consumes less than $10 \mathrm{~mA}$ in transmission mode and $22 \mathrm{~mA}$ in receiving mode. It is equipped with Ethernet, Wi-Fi connectivity, and USB. Thus, the design addresses ultra-low power, high throughput, and universal connectivity. The quality of the recorded ECG signal (Fig. 4) is quite superior due to innovative ECG and wireless sensors.
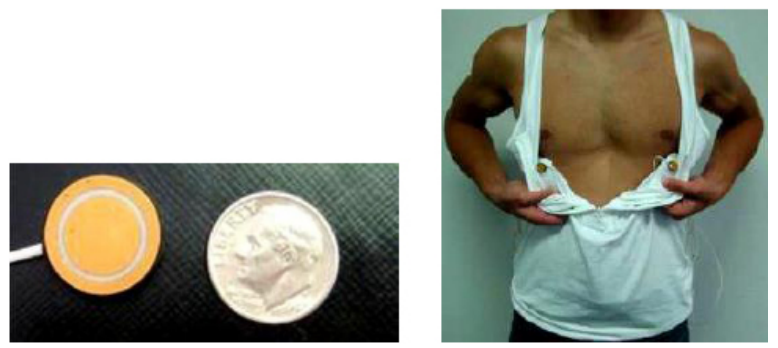

Fig. (3). (a) QUASAR ECG Sensors, (b) T-shirt with sensors by Park [4] Copyright CIEEE 2006.

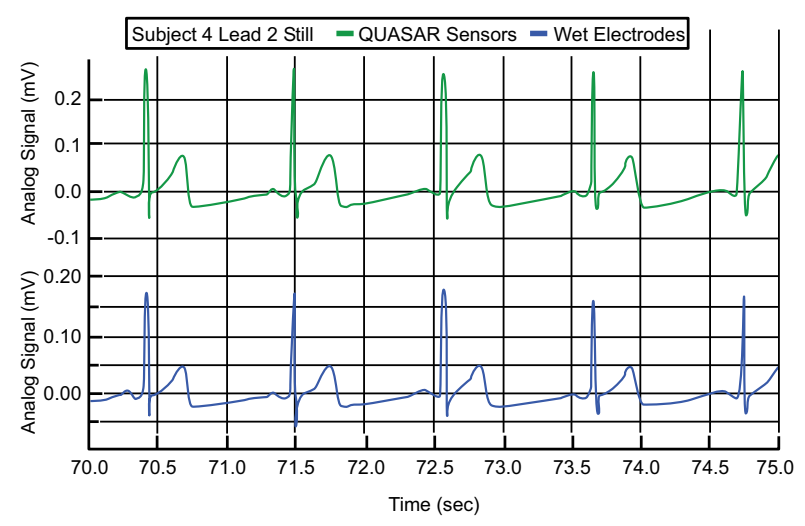

Fig. (4). Data Comparison: QUASAR (green); conventional electrode (blue) [4] Copyright (C) IEEE 2006.

Chen et al. [5] have developed a Mobicare Cardio Monitoring System for ambulatory and continuous detection. The system, as shown in Fig. (5), consists of a wireless ECG sensor, cellphone, a user interface, a patients' database, and a web-based server. It helps a CVD patient to detect abnormalities and thereby to monitor his heart status. The system captures single-lead ECG, accelerometer signals and transmits them via Bluetooth to the cellphone. The distinguishing feature of this system is the real-time ECG processing algorithm (MobiECG) that includes QRS detection, the onset of $\mathrm{Q}$ wave and offset of $\mathrm{T}$ wave detection, and intensity of patient's body movements using accelerometer data. The MobiECG transmits only abnormal ECG data to hospitals or care centres over a cellular network (GPRS/3G). Normal ECG data will not be transmitted in order to avoid telecommunication channel flooding.

New wireless technology for tele-homecare purposes proposed by Fensli et al. [6] (Fig. 6) gives better overall monitoring performance and patient care. It gives the patient freedom for mobility and still be under continuous monitoring. They have described a concept of transmitting wireless and wearable ECG signals to the hospital diagnostic station. This concept is intended to detect the cardiac arrhythmias that rarely occur in the patients at home carrying their day-to-day activities. 


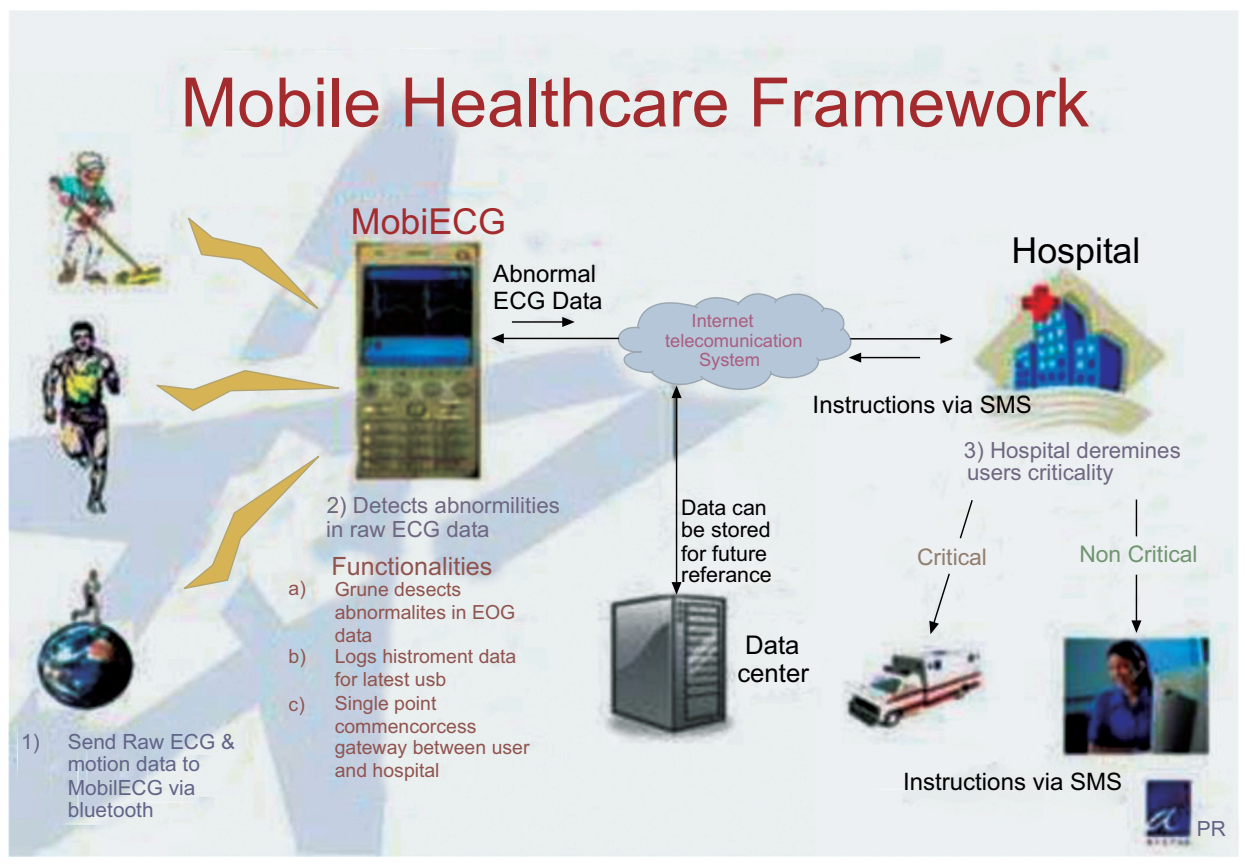

Fig. (5). Mobicare Cardio Monitoring Framework [5] Copyright CIEEE 2007.

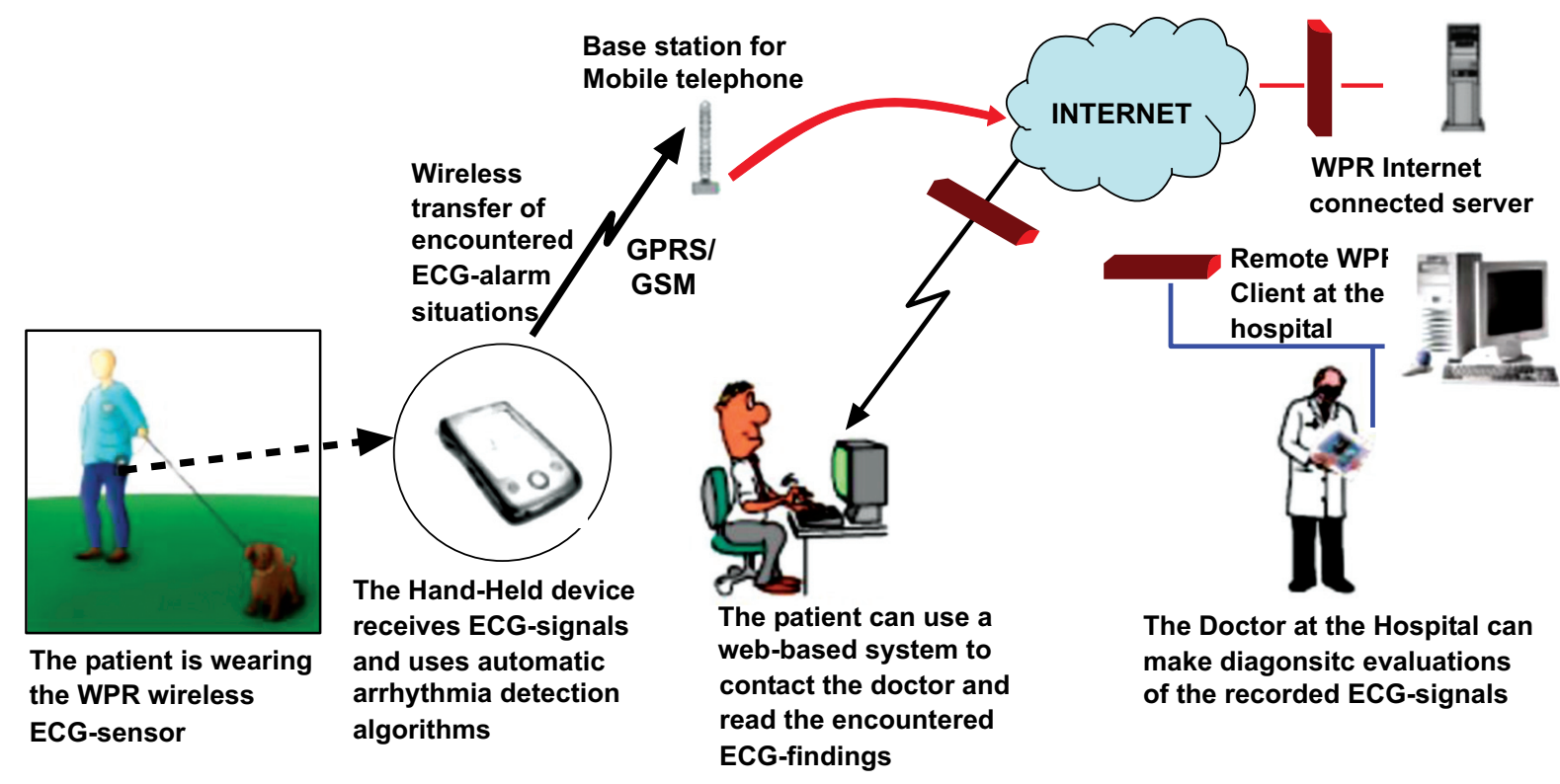

Fig. (6). Wireless ECG-system developed by Fensli et al. [6] Copyright CIEEE 2005.

In a study, the authors used multiple wearable sensors and described an online sleep/wake classification method using cardiorespiratory signals [7]. It is based on FFT as the main feature and a feed-forward ANN classifier. The method is based on the Heally recording system, as shown in Fig. (7), and records ECG and respiratory signals. This portable recording system uses gel electrodes for measuring a single-lead ECG sampled at $100 \mathrm{~Hz}$ and an inductive belt sensor for measuring respiratory effort sampled at $50 \mathrm{~Hz}$. Additionally, the Heally system is also capable of recording EMG from the right shoulder muscle at $200 \mathrm{~Hz}$ and EOG at $200 \mathrm{~Hz}$. As shown in Fig. (7), ECG gel electrodes, inductive belt sensor, electronic modules, and NiMH battery are indicated by 1, 2,3, and 4 , respectively. 


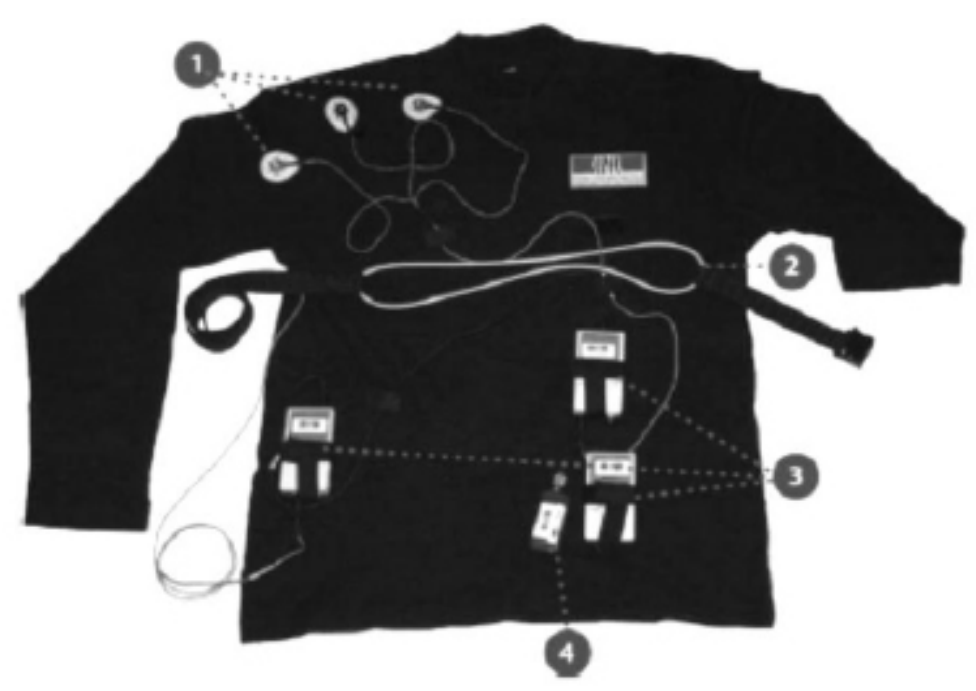

Fig. (7). Heally recording system [7] Copyright @IEEE 2009.

It is quite awkward to place wearable sensors at multiple body locations, particularly when the user is required to collect the data daily for longer periods. Authors have proposed $[8$ 12] many approaches based on multiple integrated sensors, as it is quite comfortable to wear a single device for the user. Integrating multimodal information can yield additional parameters such as temperature, heart rate, skin resistance, GPS location, etc. Ming Li et al. [13] have proposed a multimodal wearable sensor-based physical activity recognition system using the KNOWME network, as shown in Fig. (8). The KNOWME [14] network utilizes heterogeneous sensors- accelerometer, heart rate, blood oxygen levels, and ECG simultaneously, which send their measurements to a Nokia N95 cell phone via Bluetooth. Moreover, external sensor data are combined with data from the mobile phone's built-in sensors (GPS and accelerometer signal). Thus, the mobile phone can display and transmit the combined health record to a back-end server (e.g., Google Health Server) in real-time.

In several studies, the authors have implemented various algorithms for the data/ signals acquired from various types of wearable health monitoring systems [15 - 34]. In one study, an integrated ECG signal-processing scheme is proposed [35]. The system implements multiple real-time signal processing functions, like a baseline and other noise removals, QRS detection, heart rate prediction/classification using a systematic wavelet transform algorithm. This low-cost hardware architecture is implemented using ASICs with $0.18 \mu \mathrm{m}$ CMOS technology and is very much suitable for long-term cardiac monitoring due to its extremely low power consumption feature.

A windows smartphone-based wearable CVD detection system, HeartToGo, has been developed [36]. It is capable of real-time ECG acquisition and display, feature extraction, and beat classification. The system can detect the premature ventricular contraction (PVC) beats and generate the cardiac summary report that consists of the maximum/ minimum and average heart rate, as well as the number of normal and PVC beats, as shown in Fig. (9). In several studies, more or less similar wearable recorders using varieties of sensors and technologies have been described [37 - 40].

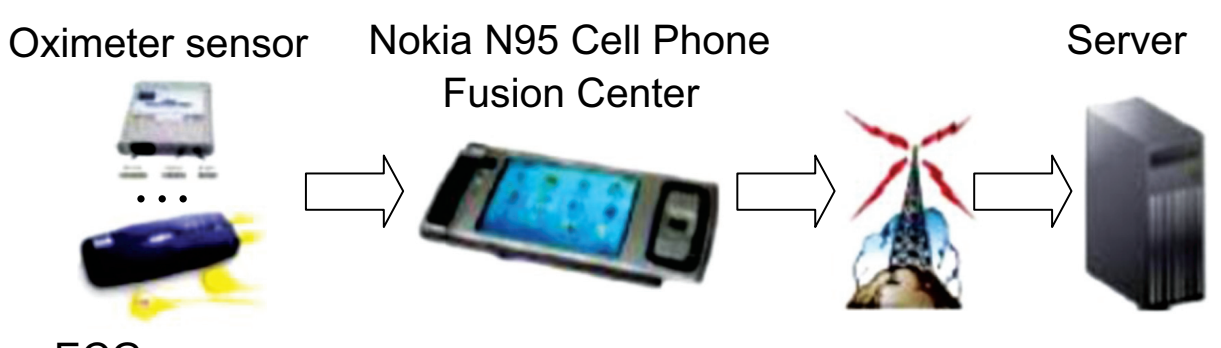

ECG sensor

Fig. (8). KNOWME WBAN system [13,14] Copyright CIEEE 2010. 

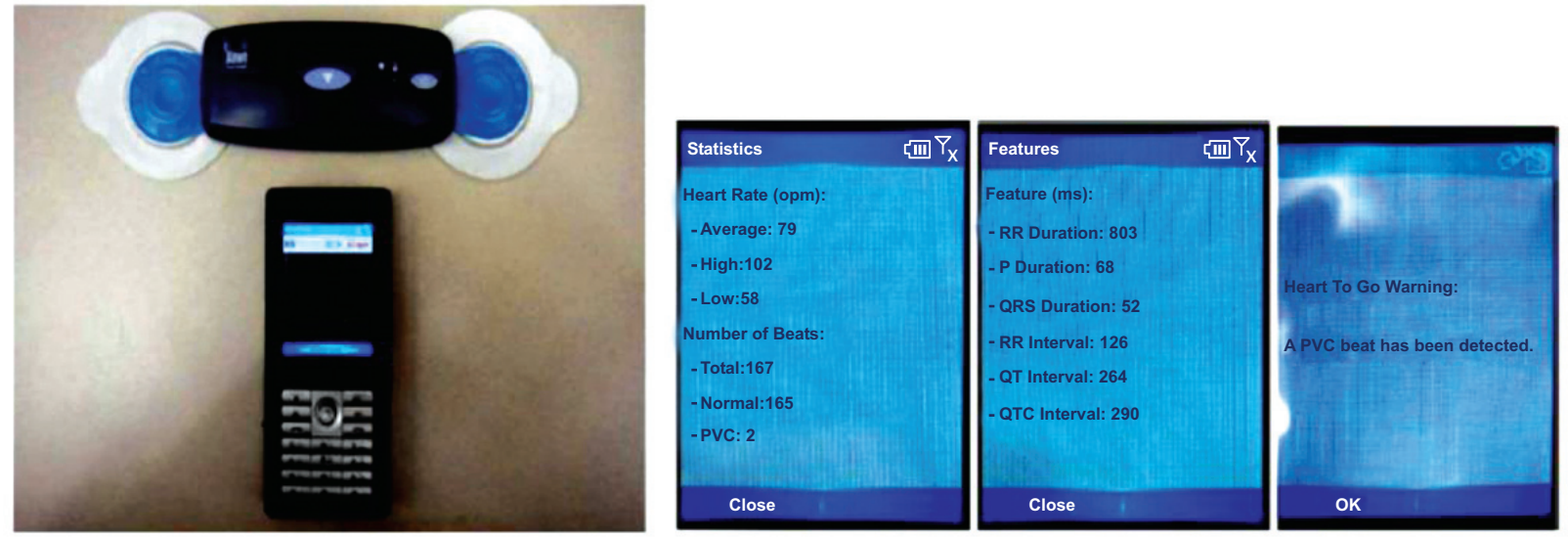

Fig. (9). HeartToGo system and readings [36] Copyright CIEEE 2010.

Xin Liu et al. [41] have designed an ultra-low power ECG acquisition and monitoring system for WBAN applications. The system shown in Fig. (10) can accurately record and detect the QRS peaks of the ECG waveform with high-frequency noise suppression. The proposed system is implemented in 0.18- $\mu \mathrm{m}$ CMOS technology with two chips: analog front end
IC and digital ASIC. The analog IC with an area of $4.25 \mathrm{~mm}^{2}$ consumes only $79.6 \mu \mathrm{W}$, and the digital ASIC consumes $9 \mu \mathrm{W}$ at $32 \mathrm{kHz}$ with $1.2 \mathrm{~mm}^{2}$. Therefore, this ECG sensor node is convenient for long-term monitoring of the cardiovascular condition of patients and WBAN applications.
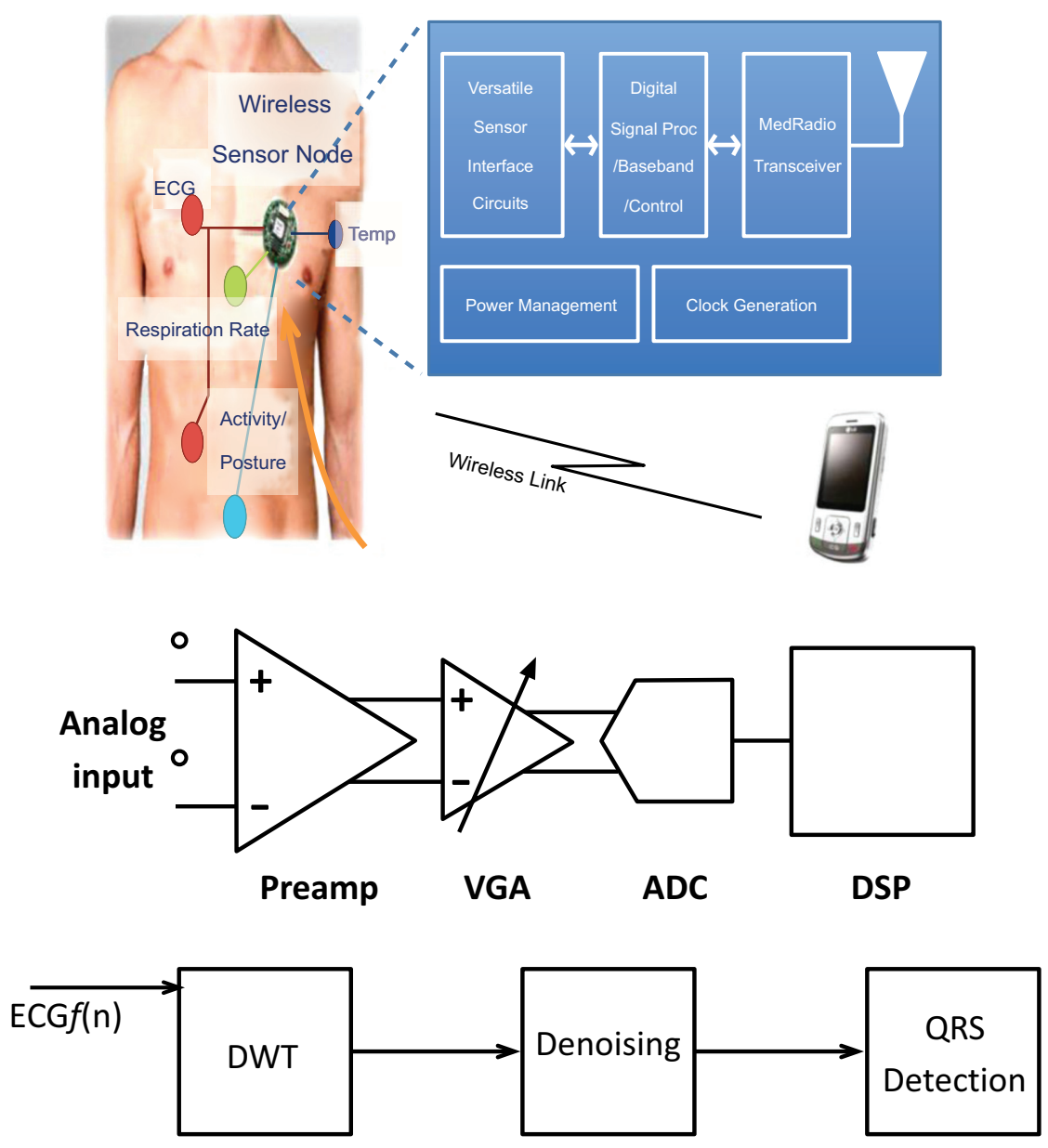

Fig. (10). An ultra-low-power ECG acquisition and monitoring ASIC system for WBAN applications [41]. 
Patel developed a wearable recorder for acquiring ambulatory ECG and physical movements using an accelerometer sensor [42]. It is a single-lead ECG recording system with a spectrum of $0.05 \mathrm{~Hz}$ to $250 \mathrm{~Hz}$. It has been implemented using ultra-low power MSP430 microcontroller with 12-bit ADC and ZigBee wireless connectivity. The signal conditioning unit consists of an instrumentation amplifier (INA 321) with a CMRR of $94 \mathrm{~dB}$ up to $3 \mathrm{kHz}$. Followed by INA
321 are the low-pass and high-pass filters for removing the high-frequency noise and baseline wander, respectively. The filters are implemented by the two in-built op-amps of MSP430, exploring its mixed-signal processing capability. The filtered and digitized ECG signal is then transferred to the nearby base station (laptop) serially via the Zigbee channel at a baud rate of aa5.2 kbps. Fig. (11) below shows the developed GUI and acquired ambulatory ECG signals.

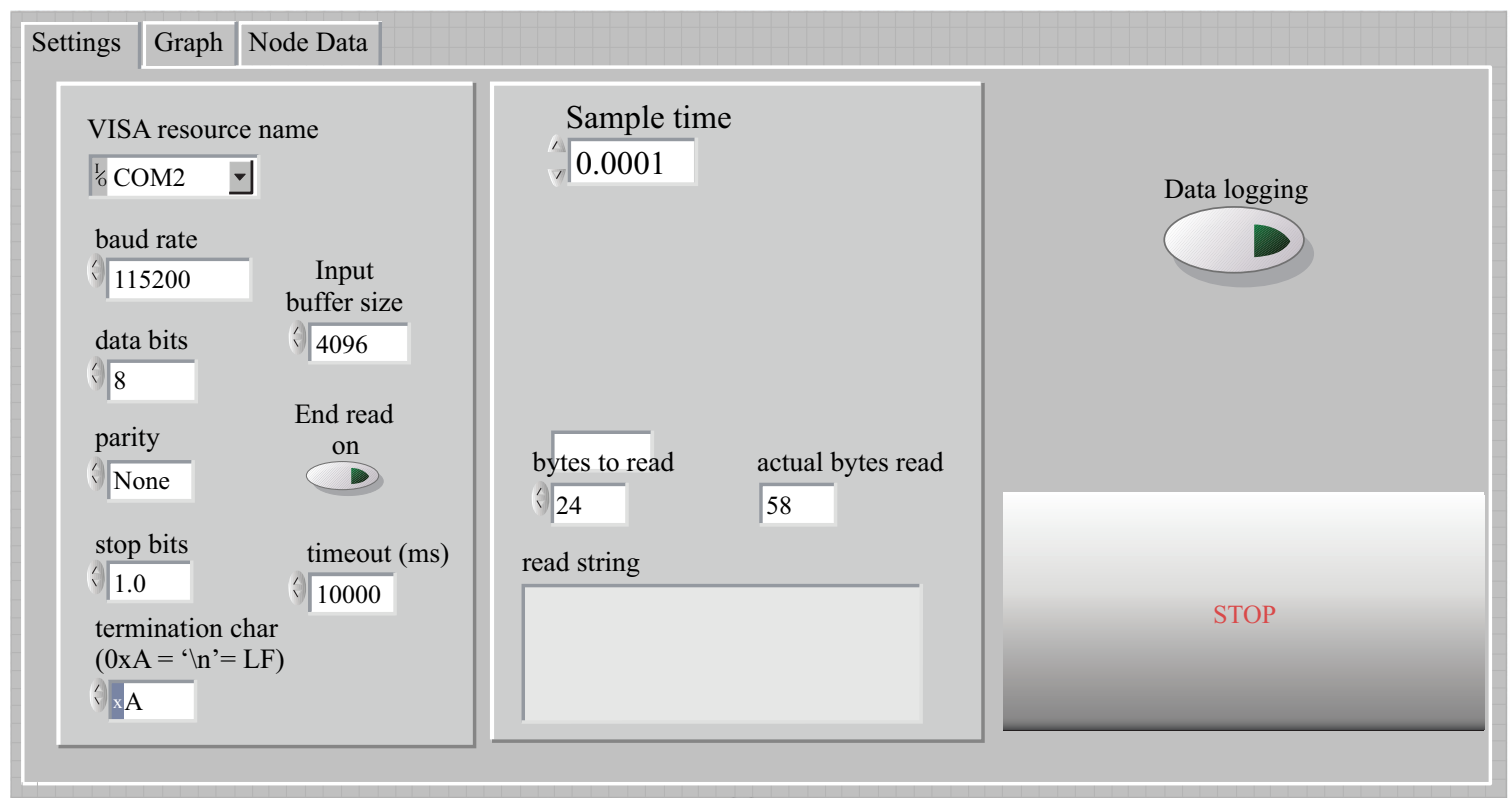

A

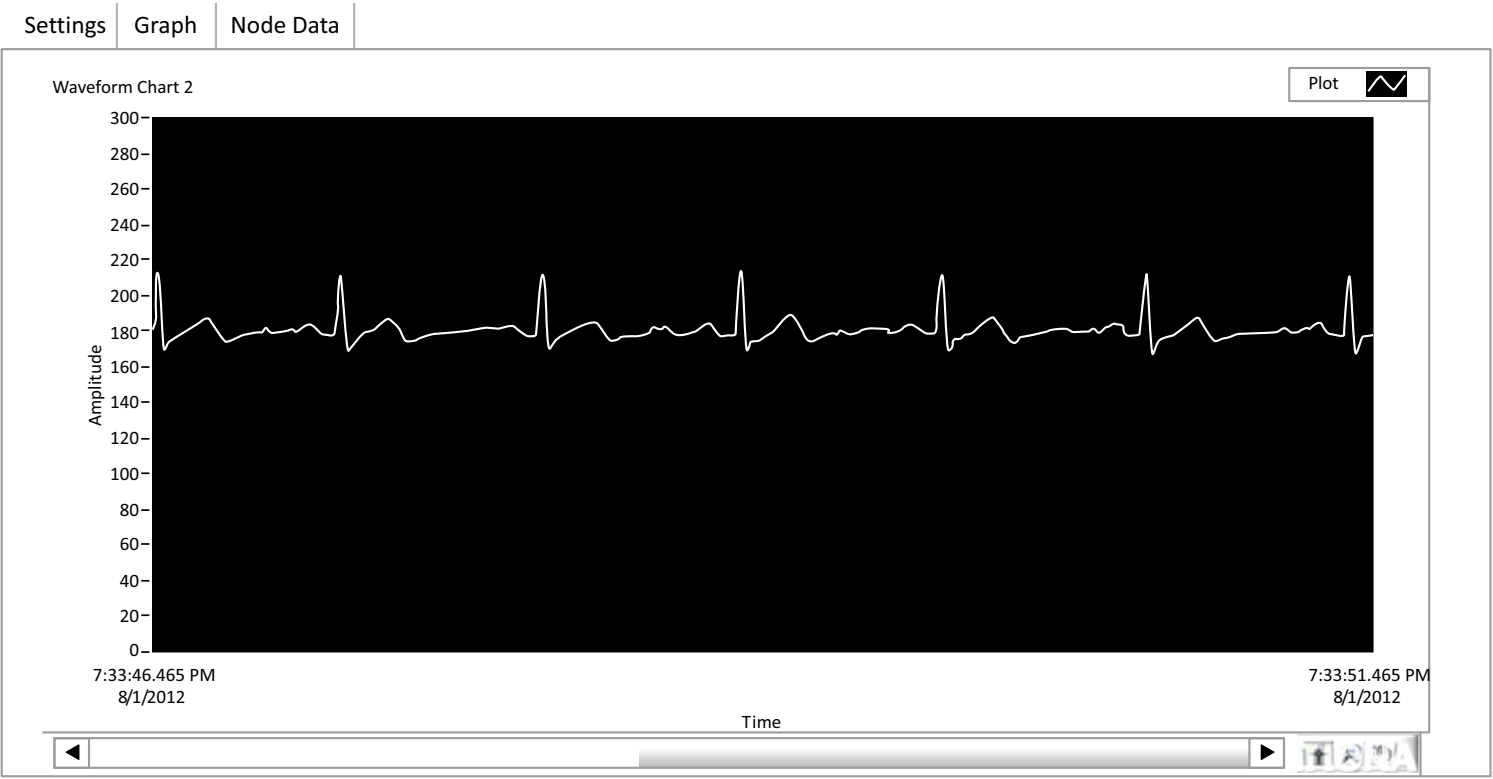


Settings Graph Node Data

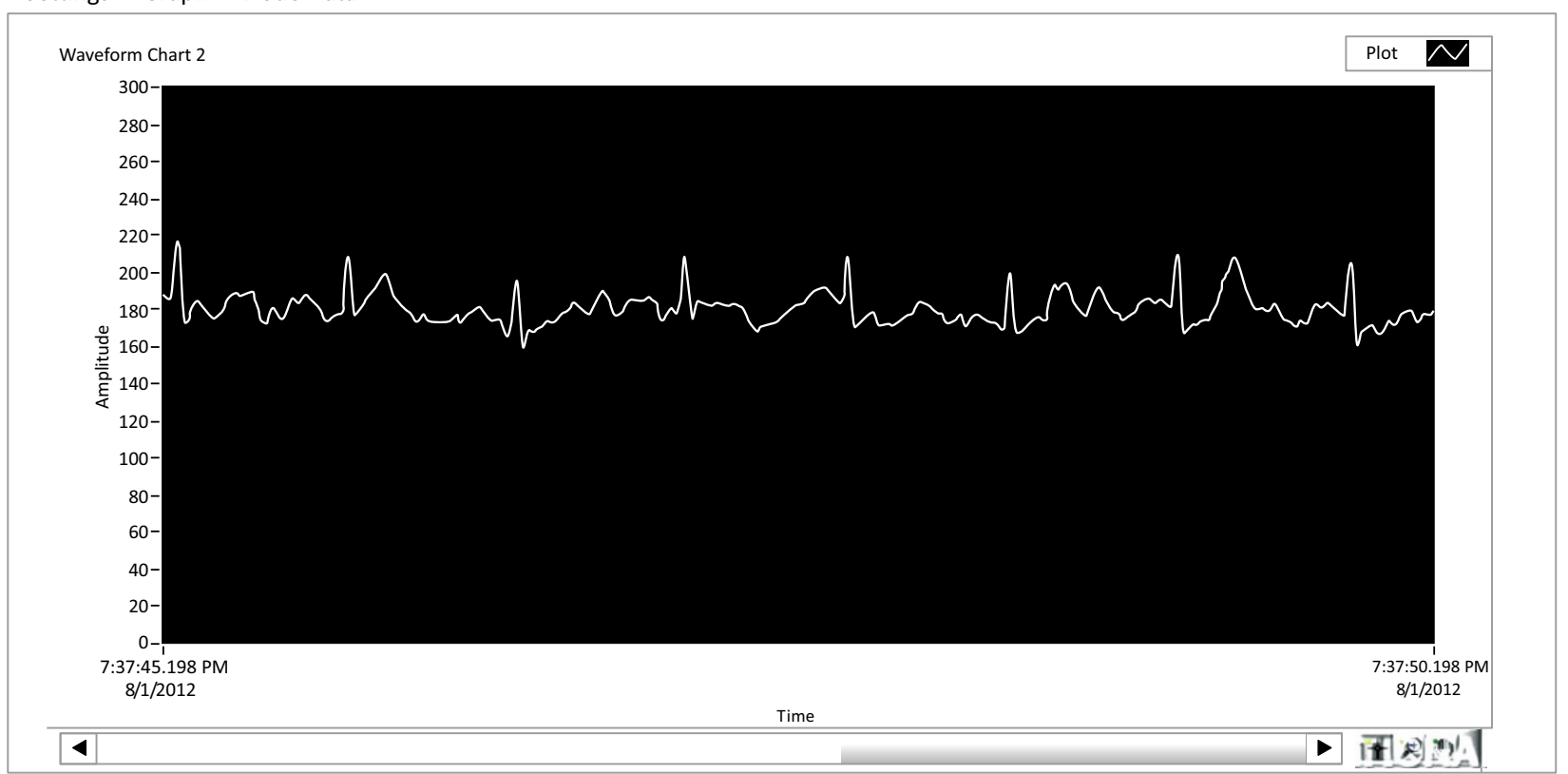

C

Fig. (11). (a) Front panel of GUI developed in Labview; (b) Ambulatory ECG signal acquired during standing still position (c) Ambulatory ECG signal for slow motion walking [42].

Nirav Patel and R Kher developed a health monitoring system with an android app to monitor ECG, EEG, body temperature, and $\mathrm{SpO}_{2}$ [43]. The developed system is low-cost and reliable, implemented using an MSP430 microcontroller. The system not only displays ECG/ EEG signals and temperature/ $\mathrm{SpO}_{2}$ parameters on the smartphone screen but also generates an alert message when the temperature and heartbeat values are outside the critical range. The system is incorporated with a facility to upload the recorded data on Dropbox. Fig. (12) below show the recorded ECG, EEG, $\mathrm{SpO}_{2}$, and body temperature displayed on an android mobile screen.

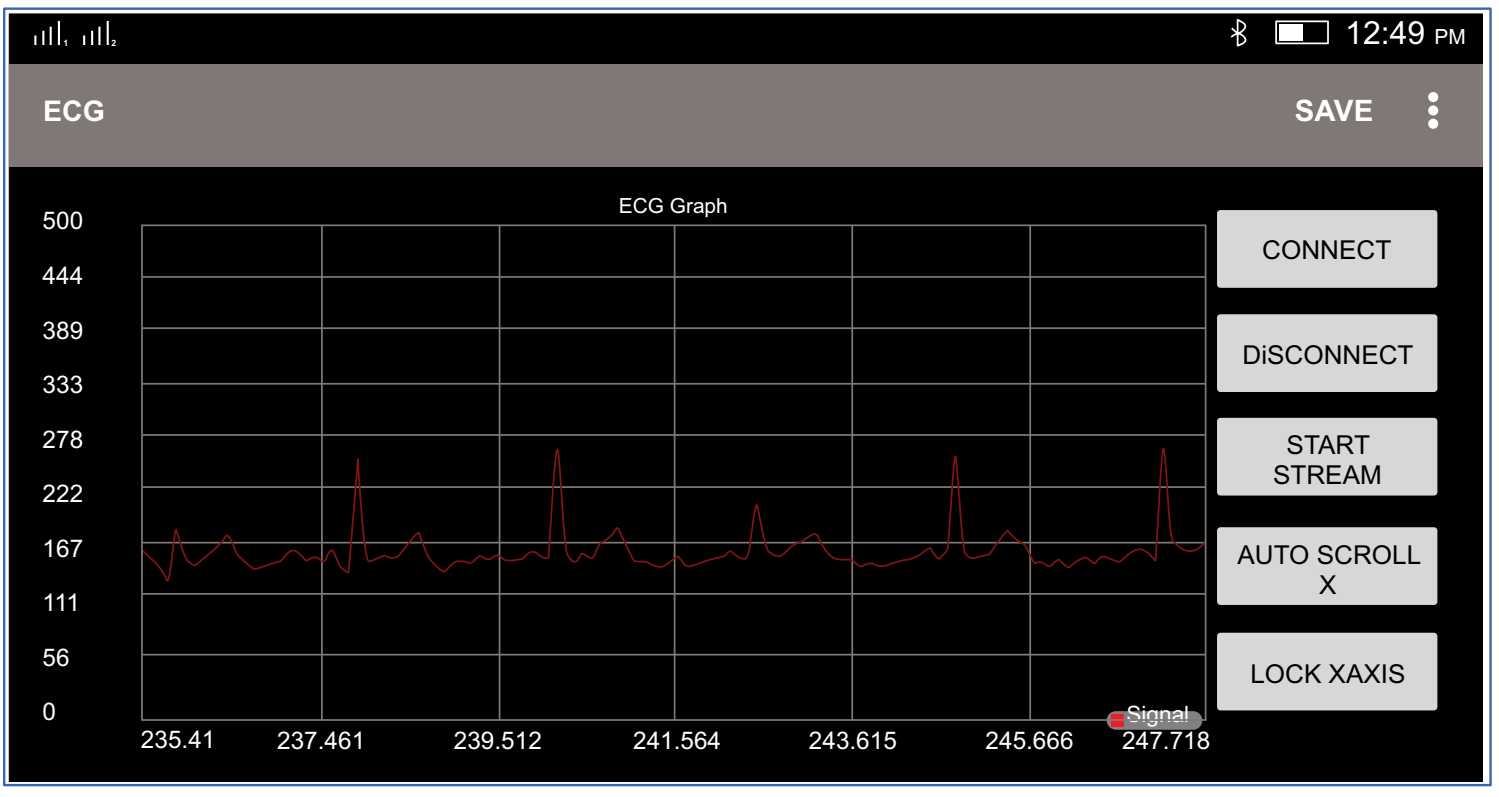




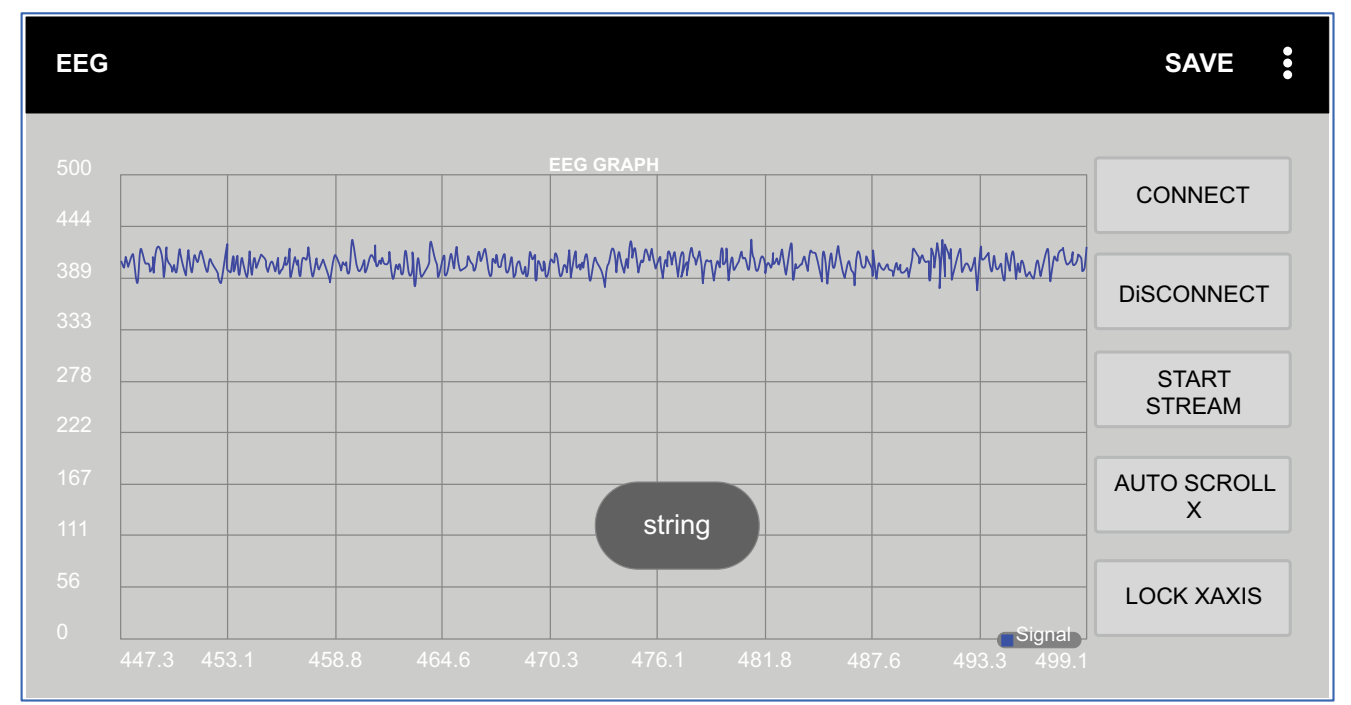

B

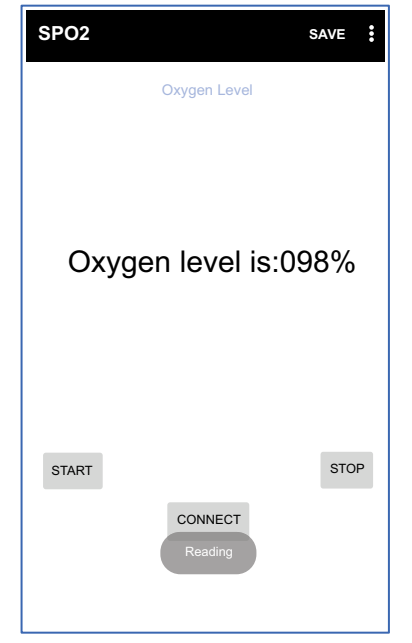

(c)

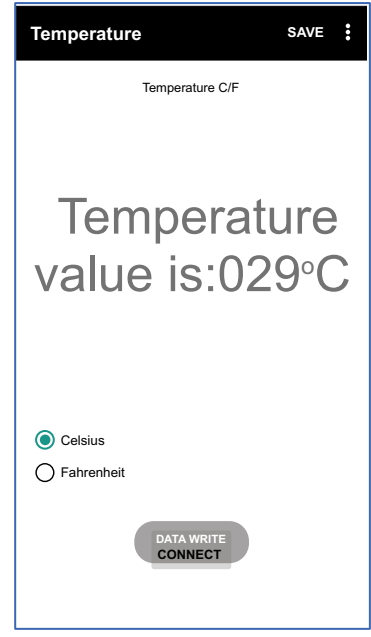

(d)

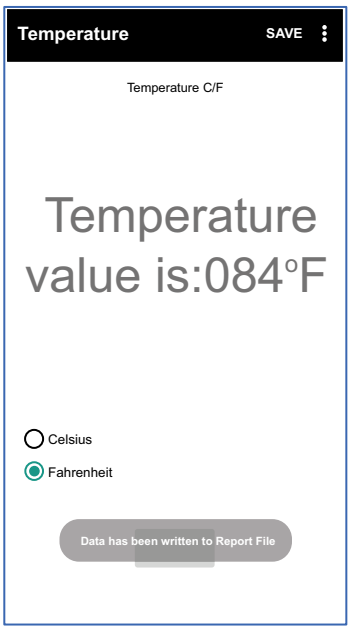

(e)

Fig. (12). Recorded ECG and EEG signals in (a) and (b); SpO2 and temperature values in (c), (d) and (e) [43].

Kher et al. developed a portable, low-cost wearable system for recording ECG signals of a subject [44]. Two separate prototype designs for recording single lead and 12-lead ECG (Fig. 13) have been implemented using ADS 1298 and STM32L431RCT6 microcontroller. The STM32L431RCT6 is a 32-bit ARM cortex-M4 microcontroller from ST Microelectronics. ADS 1298 is a 24-bit analog front end by Texas Instruments for biopotential acquisition, especially for ECG and EEG recording. It has 8-channel ADC, an inbuilt right leg drive amplifier with SPI compatible serial interface. The recorded ECG signal is sent to the computer/ laptop via Bluetooth as well as displayed on the OLED display. The lowcost, portable system could be used for long-term monitoring of ECG signals to avoid hospitalization. The physicians can also use the system for the first-hand monitoring of cardiac abnormalities of a subject.

Incorporating IoT is the latest technological enhancement in wearable health monitoring systems. With continuous monitoring provided by IoT technologies and real-time alerts, patients and their families feel safe and secure even being at a remote home. Jie et al. [45] have devised the Wearable IoTcloud-baSed hEalth monitoring system (WISE) for real-time personal health monitoring. WISE adopts the body area sensor network- the heartbeat, body temperature, and blood pressure sensors. The WISE system eliminates the use of a smartphone as data gathered from the BASN are directly transmitted to the cloud. A lightweight, wearable LCD may be used to have a quick look at the real-time data. Fig. (14) depicts the block diagram and architecture of the WISE system. 


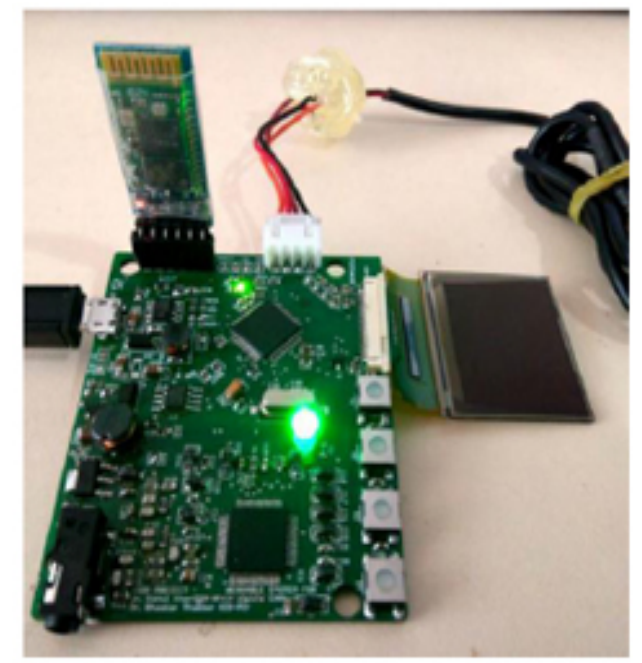

(a)

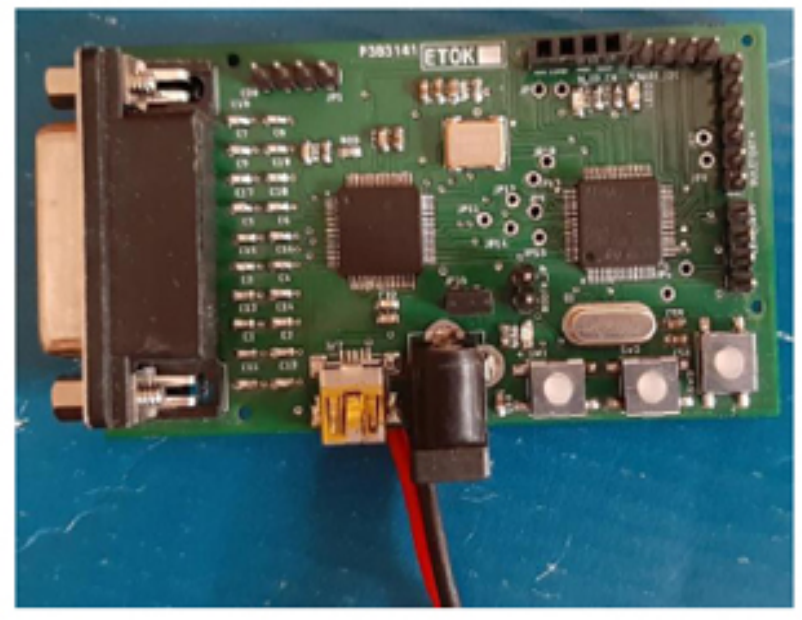

(b)

Fig. (13). (a) Prototype 1 and (b) Prototype 2 developed by Kher et al. [44].

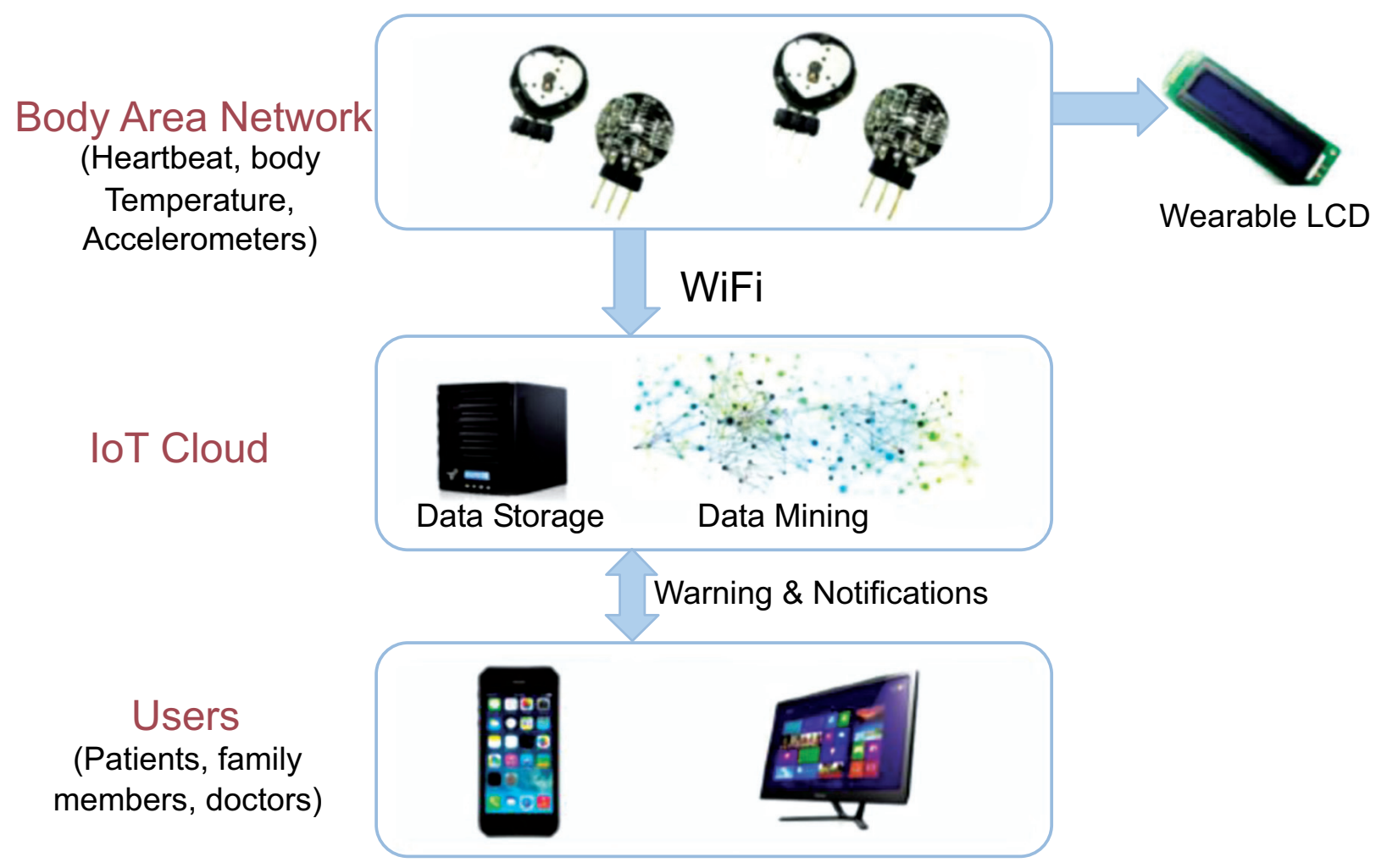

(a) 


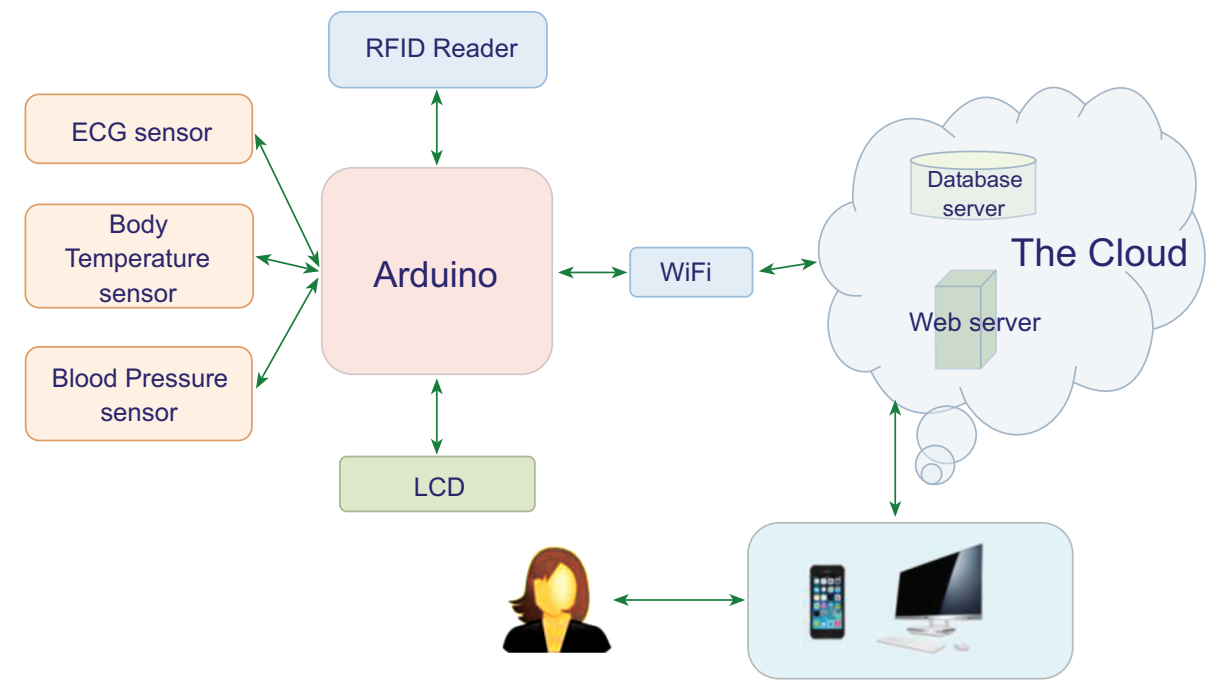

(b)

Fig. (14). The WISE system: (a) framework and (b) block diagram [45] @ Jie Wan et. al.

IoT has been incorporated for developing personal healthcare devices, Parkinson's and Alzheimer's disease diagnosis and monitoring systems, student healthcare monitoring systems, cloud-based framework to control Ebola virus outbreak, wearable ECG monitoring system, human activity recognition assembly, etc [46 - 54].

\section{COMMERCIAL ASPECTS AND SMART TECHNOLOGIES IN WEARABLE SYSTEMS}

Once considered an entity for research, the wearable devices/wearables are now commercially available. This section describes commercially available gadgets that are already in use or will be in use in the near future, the latest trends in wearables medical devices, and the key challenges.

\subsection{Smart Wearable Gadgets}

\subsubsection{Smartwatches}

One of the most widely used wearables today are smartwatches due to their numerous features. If it is connected with a smartphone, then most of the smartphone functions like picking a call, reading a message, activity monitoring, etc. are performed, thus eradicating the necessity to hold and view one's phone. Smartwatch manufacturers are adding more and more features: Apple's iWatch enables users to obtain an ECG reading without any additional accessories. Similarly, the Matrix PowerWatch Series 2 can charge from body heat and solar power instead of electricity [54]. There are many apps supporting smartwatches from Apple, LG, Samsung and others which offer exciting features [55].

\section{SMART JEWELLERY}

Currently research is being conducted on healthmonitoring functionalities in smart jewellery. The smart ring is the most prominent kind of smart jewellery as of now. Jewellery brands like Oura have already introduced smart rings that can track health data of the user and the same can later be reviewed on a smartphone. Many other smart jewellery options like bangles and bracelets are being designed by well-known fashion firms. The Joule have come up with a range of smart health-tracking earrings [54].

\section{FITNESS TRACKERS}

The fitness trackers are widely used to monitor the number of steps, calories burned, heart rate, and a range of other parameters. It is difficult to clearly distinguish the fitness tracking devices and smartwatches as products such as FitBit's now include smartwatch features like call and message alerts in addition to fitness-oriented features. On the other hand, smartwatches are equipped with many fitness tracking options. Fitness trackers are becoming cheaper due to fewer features as their main focus is on functionality rather than artistic appeal [54].

\section{SMART CLOTHING}

Instead of using smaller wearables, smart clothing can provide more detailed perceptions by including a large number of body sensors. Samsung has conducted wide research in this sector and may soon come up with smart shirts with respiratory diseases diagnostic capabilities and smart shoes that monitor running methods. Among available smart clothing are Siren Socks, which detect foot ulcers, smart pants that vibrate for improvising during yoga workouts and Naviano smart swimsuits that provide the user about when to apply sunscreen.

Companies have started generating brand loyalties by using smart clothing, e.g., Tommy Hilfiger introduced location-tracking functionality in their Xplore range of jeans. The company would reward more Tommy Hilfiger products to the customers who have worn the product more frequently [54]. 


\section{IMPLANTABLES}

Unlike wearables, implantables are to be swallowed or inserted inside the user's body rather than measuring the parameters from the skin. For instance, Proteus produces pills contain sensors that can monitor blood pressure and other health parameters [54].

\subsection{New and Emerging Wearable Medical Devices}

Wearable devices and smart wearables are convenient for monitoring various physiological parameters, and they help in a multitude of medical solutions. Besides their ease of operation, they provide data in real-time, which can be analyzed by the physicians. Wearable medical technologies have a wide range of healthcare- from ECG to glucose monitoring. They are now artificial intelligence (AI) enabled and have become more powerful. They have recently received FDA clearance for patients to use them at home [56]. The following paragraphs describe emerging wearable devices and the latest applications in health monitoring.

Alzheimer's patients have impairment in walking mechanics or gait. In patients suffering from Alzheimer's disease, gait speed, stride length, and symmetry are naturally reduced. The sensors in smartphones/watches/other wearable devices can continuously monitor one's walking habits and provide an accurate measure of the patient's gait. This information can be further enhanced with the help of pressure readings provided by the contact sensors in a shoe or socks.

A waterproof, bandage-like sweat sensor has been developed by the researchers that informs the wearer when to intake fluids or electrolytes. This innovative patch is based on sweat analysis technology. It collects and analyzes athlete's perspiration resulting from exercise/ swimming and sends it to the small holes under the patch. Each hole tests various metrics to analyze if the wearer needs hydration or electrolytes.

The researchers from the University of Michigan have created a wearable device that can collect and observe circulating tumour cells (CTCs) contained in the blood. Usually, these cells are obtained from blood samples, but this wearable device worn on the wrist could screen patients' blood for a few hours to obtain the CTCs of interest only. Singaporebased medical technology company- AWAK Technologies has recently developed a wearable, portable dialysis device. The device known as AWAK Peritoneal Dialysis device (AWAK PD) uses AWAK's patented sorbent technology and provides a suitable method of dialysis for patients with renal diseases.

\section{KEY CHALLENGES IN WEARABLES}

The biggest challenge for wearable technology is to get sustained customers. Many wearable systems have a short life because its consumers are not sustained. Poor battery life, sync issues with smartphones, awful and uncomfortable design, UX problems are some of the major challenges associated with wearable devices. Thus, despite being very strong functionally and physically, the wearable devices fail to create any meaningful impact on the users, their lives, habits, or behaviours [57].

One of the biggest challenges faced by wearable systems today is battery life. Effective power management is required in wearable devices as battery space is limited, and they are required to run for a long time. The comfortable design of wearable devices is of prime importance, especially when they are to be worn for a long time period. Wearable systems/ devices are frequently exposed to water, sweat, etc.; hence, they require different levels of protection.

Integration of radio and Antennae is another challenge with wearable devices, given the small form factor of these products. Effective integration of multiple antennae with reasonable signal strength and compact packing of hardware in a small size is quite difficult. There is a potential safety risk as wearable devices contain lithium batteries which are close to the body at all times. There have been many incidents that involve batteries catching fire and Fitbits damaging wrists due to explosions. Other challenges with wearable devices are radiations emitted at close proximity to vital organs of the body, security and privacy concerns, hacking and manipulation of user data due to lack of encryption [58 - 67].

\section{CONCLUSION}

A comprehensive review of wearable health monitoring systems has been presented here. Researchers have developed wearables systems mainly for recording ECG, heart rate, $\mathrm{SpO}$, etc. Gradually, other attachments like wireless transmission of recorded health data over distant places have been added. With ever-growing technological advancements, they soon became commercially available. Very soon, smartphone and gadget manufacturers like Apple, Samsung, Xiaomi started incorporating the health monitoring features in their devices in miniaturised forms. The wearables like smart clothes and smart jewellery have also been becoming popular among other smart gadgets that incorporate health monitoring capabilities. IoT can be considered as the latest technological addition in wearable health monitoring systems. In the future, IoT-based health monitoring systems will alert families and doctors immediately as soon as issues arise, providing increased mobility and independence to the patients.

\section{CONSENT FOR PUBLICATION}

Not applicable.

\section{FUNDING}

None.

\section{CONFLICT OF INTEREST}

The authors declare no conflict of interest, financial or otherwise.

\section{ACKNOWLEDGEMENTS}

Declared none.

\section{REFERENCES}

[1] V. Vaid, "A silicon locket for ECG Monitoring", M.Tech Thesis, Department of Electrical Engineering, Indian Institute of Technology Bombay: Powai, Mumbai, 2013.

[2] M. Shojaei-Baghini, R.K. Lal, and D.K. Sharma, "A low-power and compact analog CMOS processing chip for portable ECG recorders", Asian Solid-State Circuit Conference, A-SSCC'05, Hshinchu, Taiwan, 
Nov., 2005

[http://dx.doi.org/10.1109/ASSCC.2005.251768]

[3] Y. Okada, Y-T. Yoto, T-A. Suzuki, T. Sugiura, and S. Sakuragawa, "Development of a wearable ECG recorder for measuring daily stress", International Conference on Information Science and Applications (ICISA), 2010pp. 1-5 Seoul, Korea

[http://dx.doi.org/10.1109/ICISA.2010.5480419]

[4] C. Park, P.H. Chou, Y. Bai, R. Matthews, and A. Hibbs, "An ultrawearable wireless low power ECG monitoring system", Biomedical Circuits and Systems Conference (BioCAS 2006), pp. 241-244 London, UK

[http://dx.doi.org/10.1109/BIOCAS.2006.4600353]

[5] X. Chen, C.T. Ho, E.T. Lim, and T.Z. Kyaw, "Cellular phone based online ECG processing for ambulatory and continuous detection", In: Computers in Cardiology, Durham, NC, USA, 2007, pp. 653-656. [http://dx.doi.org/10.1109/CIC.2007.4745570]

[6] R. Fensli, E. Gunnarson, and T. Gundersen, "A wearable ECGrecording system for continuous arrhythmia monitoring in a wireless tele-home-care situation", 18th IEEE Symposium on Computer based Medical Systems, 2005pp. 407-412

[http://dx.doi.org/10.1109/CBMS.2005.22]

[7] W. Karlen, C. Mattiussi, and D. Floreano, "Sleep and wake classification with ECG and respiratory effort signals", IEEE Trans. Biomed. Circuits Syst., vol. 3, no. 2, pp. 71-78, 2009. [http://dx.doi.org/10.1109/TBCAS.2008.2008817] [PMID: 23853198]

[8] J. Lester, T. Choudhury, and G. Borriello, "A practical approach to recognizing physical activities", Lect. Notes Comput. Sci., vol. 3968, pp. 1-16, 2006.

[http://dx.doi.org/10.1007/11748625_1]

[9] P. Lukowicz, H. Junker, M. Stager, T. Von Buren, and G. Troster, "Wear- NET: A distributed multi-sensor system for context aware wearables", Lect. Notes Comput. Sci., pp. 361-370, 2002. [http://dx.doi.org/10.1007/3-540-45809-3_28]

[10] J. Pärkkä, M. Ermes, P. Korpipää, J. Mäntyjärvi, J. Peltola, I. Korhonen, V. Technol, and F. Tampere, "Activity classification using realistic data from wearable sensors", IEEE Trans. Inf. Technol. Biomed., vol. 10, no. 1, pp. 119-128, 2006.

[http://dx.doi.org/10.1109/TITB.2005.856863] [PMID: 16445257]

[11] M. Ermes, J. Pärkka, J. Mantyjarvi, and I. Korhonen, "Detection of daily activities and sports with wearable sensors in controlled and uncontrolled conditions", IEEE Trans. Inf. Technol. Biomed., vol. 12, no. 1 , pp. 20-26, 2008.

[http://dx.doi.org/10.1109/TITB.2007.899496] [PMID: 18270033]

[12] M. Annavaram, N. Medvidovic, U. Mitra, S. Narayanan, G. Sukhatme, Z. Meng, S. Qiu, R. Kumar, G. Thatte, and D. Spruijt-Metz, "Multimodal sensing for pediatric obesity applications", International Workshop on Urban, Community, and Social Applications of Networked Sensing Systems (UrbanSense), 2008pp. 21-25 Raliegh, NC, USA

[13] M. Li, V. Rozgica, G. Thatte, S. Lee, A. Emken, M. Annavaram, U. Mitra, D. Spruijt-Metz, and S. Narayanan, "Multimodal physical activity recognition by fusing temporal and cepstral information", IEEE Trans. Neural Syst. Rehabil. Eng., vol. 18, no. 4, pp. 369-380, 2010.

[http://dx.doi.org/10.1109/TNSRE.2010.2053217] [PMID: 20699202]

[14] S. Lee, M. Annavaram, and G. Thatte, "R. V., M. Li, U. Mitra, S. Narayanan, and D. Spruijt-Metz, "Sensing for obesity: KNOWME implementation and lessons for an architect", Proceedings of the workshop on biomedicine in computing: Systems, architectures, and circuits (BiC), 2009 Austin, USA

[15] D-U. Jeong, and S-J. Kim, "Development of a technique for cancelling motion artifact in ambulatory ECG monitoring system", $3^{\text {rd }}$ International Conference on Convergence and Hybrid Information Technology (ICCIT), pp. 954-961 Busan, Korea

[http://dx.doi.org/10.1109/ICCIT.2008.315]

[16] Y-D. Lee, S-J. Jung, Y-S. Seo, and W-Y. Chung, "Measurement of motion activity during ambulatory using pulse oximeter and triaxial accelerometer", $3^{\text {rd }}$ International Conference on Convergence and Hybrid Information Technology (ICCIT), pp. 436-441 Busan, Korea [http://dx.doi.org/10.1109/ICCIT.2008.388]

[17] A. Sharma, and A. Purwar, "Young-Dong Lee, Young-Sook Lee and Wan-Young Chung, "Frequency based classification of activities using accelerometer data", Proceedings of IEEE International Conference on Multisensor and Integration for Intelligent Systems, pp. 150-153 Seoul, Korea

[18] W.H. Wu, A.A. Bui, M.A. Batalin, L.K. Au, J.D. Binney, and W.J. Kaiser, "MEDIC: medical embedded device for individualized care",
Artif. Intell. Med., vol. 42, no. 2, pp. 137-152, 2008.

[http://dx.doi.org/10.1016/j.artmed.2007.11.006] [PMID: 18207716]

[19] S.A. Akar, S. Kara, F. Latifo glu, and V. Bilgic,, "Spectral analysis of photoplethysmographic signals: The importance of preprocessing", Biomed. Signal Process. Control, vol. 8, no. 1, pp. 16-22, 2013.

[http://dx.doi.org/10.1016/j.bspc.2012.04.002]

[20] V.X. Afonso, W.J. Tompkins, T.Q. Nguyen, and K. Michler, "Comparing stress ECG enhancement algorithms with an introduction to a filter bank based approach", IEEE Eng. Med. Biol. Mag., no. May/June, pp. 37-44, 1996.

[http://dx.doi.org/10.1109/51.499756]

[21] "Ra'ul Alcaraz, Frida Sandberg, Leif Sornmo and Jos'e Joaqu'ın Rieta, "Classification of paroxysmal and persistent atrial fibrillation in ambulatory ECG recordings", IEEE Trans. Biomed. Eng., vol. 58, no. 5, 2011.

[22] A.H. Khandoker, M. Palaniswami, and C.K. Karmakar, "Support vector machines for automated recognition of obstructive sleep apnea syndrome from ECG recordings", IEEE Trans. Inf. Technol. Biomed., vol. 13 , no. 1 , pp. 37-48, 2009.

[http://dx.doi.org/10.1109/TITB.2008.2004495] [PMID: 19129022]

[23] D-H. Shih, H-S. Chiang, B. Lin, and S-B. Lin, "An embedded mobile ECG reasoning system for elderly patients", IEEE Trans. Inf. Technol. Biomed., vol. 14, no. 3, pp. 854-865, 2010.

[http://dx.doi.org/10.1109/TITB.2009.2021065] [PMID: 19403370]

[24] H. Kim, R.F. Yazicioglu, P. Merken, C. Van Hoof, and H-J. Yoo, "ECG signal compression and classification algorithm with quad level vector for ECG holter system", IEEE Trans. Inf. Technol. Biomed., vol. 14 , no. 1 , pp. $93-100,2010$.

[http://dx.doi.org/10.1109/TITB.2009.2031638] [PMID: 19775975]

[25] D. Curone, A. Tognetti, E.L. Secco, G. Anania, N. Carbonaro, D. De Rossi, and G. Magenes, "Heart rate and accelerometer data fusion for activity assessment of rescuers during emergency interventions", IEEE Trans. Inf. Technol. Biomed., vol. 14, no. 3, pp. 702-710, 2010. [http://dx.doi.org/10.1109/TITB.2010.2047727] [PMID: 20378475]

[26] M. Faezipour, A. Saeed, S.C. Bulusu, M. Nourani, H. Minn, and L. Tamil, "A patient-adaptive profiling scheme for ECG beat classification", IEEE Trans. Inf. Technol. Biomed., vol. 14, no. 5, pp. 1153-1165, 2010. [http://dx.doi.org/10.1109/TITB.2010.2055575] [PMID: 20813624]

[27] J. Boyle, N. Bidargaddi, A. Sarela, and M. Karunanithi, "Automatic detection of respiration rate from ambulatory single-lead ECG", IEEE Trans. Inf. Technol. Biomed., vol. 13, no. 6, pp. 890-896, 2009. [http://dx.doi.org/10.1109/TITB.2009.2031239] [PMID: 19775978]

[28] C-T. Lin, K-C. Chang, C-L. Lin, C-C. Chiang, S-W. Lu, S-S. Chang, B-S. Lin, H-Y. Liang, R-J. Chen, Y-T. Lee, and L-W. Ko, "An intelligent telecardiology system using a wearable and wireless ECG to detect atrial fibrillation", IEEE Trans. Inf. Technol. Biomed., vol. 14 , no. 3, pp. 726-733, 2010 . [http://dx.doi.org/10.1109/TITB.2010.2047401] [PMID: 20371411]

[29] M. Zia Ur Rehman, "An efficient noise cancellation technique to remove noise from ECG signal using normalized signal regressor LMS algorithm", IEEE Int. Conf. on Bioinformatics and Biomedicine (BIBM), 2009pp. 257-260 Washington, USA

[30] P.E. Trahanias, "An approach to QRS complex detection using mathematical morphology", IEEE Trans. Biomed. Eng., vol. 40, no. 2 , pp. 201-205, 1993.

[http://dx.doi.org/10.1109/10.212060] [PMID: 8319971]

[31] "Physionet", Available at: www.physionet.org

[32] C.L. Fancourt, and J.C. Principe, "On the use of neural networks in the generalized likelihood ratio test for detecting abrupt changes in signals", Proceedings of the IEEE-INNS-ENNS International Joint Conference on Neural Networks (IJCNN 2000), 2000 Como, Italy [http://dx.doi.org/10.1109/IJCNN.2000.857904]

[33] M. Khalil, and J. Duchene, "Uterine EMG analysis: A dynamic approach for change detection and classification", IEEE Trans. on Biomed. Engg., vol. 47, no. 6, pp. 748-756, 2000.

[http://dx.doi.org/10.1109/10.844224]

[34] Y. Al-Assaf, "Surface myoelectric signal analysis: Dynamic approaches for change detection and classification", IEEE Trans. on Biomed. Eng., vol. 53, no. 11, pp. 2248-2256, 2006. [http://dx.doi.org/10.1109/TBME.2006.883628]

[35] X. Liu, Y. Zheng, M.W. Phyu, B. Zhao, M. Je, and X. Yuan, "Multiple functional ECG signal is processing for wearable applications of longterm cardiac monitoring", IEEE Trans. Biomed. Eng., vol. 58, no. 2, pp. 380-389, 2011.

[http://dx.doi.org/10.1109/TBME.2010.2061230] [PMID: 20679025]

[36] J.J. Oresko, H. Duschl, A.C. Cheng, S. Huang, Y. Sun, H. Duschl, and 
A.C. Cheng, "A wearable smartphone-based platform for real-time cardiovascular disease detection via electrocardiogram processing", IEEE Trans. Inf. Technol. Biomed., vol. 14, no. 3, pp. 734-740, 2010. [http://dx.doi.org/10.1109/TITB.2010.2047865] [PMID: 20388600]

[37] R. Richard, "Clip-on wireless wearable microwave sensor for ambulatory cardiac monitoring", $32^{\text {nd }}$ Annual International Conference of the IEEE EMBS (EMBC 2010), 2010

[38] J. Gallego, D. Lemos, G.A. Meneses, and A.M. Hernandez, "Development of a wearable vital signs monitor for healthcare", $32^{\text {nd }}$ Annual International Conference of the IEEE EMBS (EMBC 2010), Buenos Aires, Argentina, August 31 - September 4, 2010 [http://dx.doi.org/10.1109/IEMBS.2010.5627311]

[39] C.P. Figueiredo, K. Becher, K-P. Hoffmann, and P.M. Mendes, "Low power wireless acquisition module for wearable health monitoring systems", $32^{\text {nd }}$ Annual International Conference of the IEEE EMBS (EMBC 2010), Buenos Aires, Argentina, August 31 - September 4 , 2010

[http://dx.doi.org/10.1109/IEMBS.2010.5626161]

[40] S. Hwang, M. Trakimas, and S. Sonkusale, "A low-power asynchronous ECG acquisition system in CMOS technology", $32^{\text {nd }}$ Annual International Conference of the IEEE EMBS (EMBC 2010), Buenos Aires, Argentina, August 31 - September 4, 2010

[41] X. Liu, "An ultra-low power ECG acquisition and monitoring ASIC system for WBAN applications", IEEE J. Emerg. Sel. Top. Circuits Syst., vol. 2, no. 1, pp. 60-70, 2012

[http://dx.doi.org/10.1109/JETCAS.2012.2187707]

[42] D.M. Patel, Wearable systems for monitoring cardiovascular parameters., Sardar Patel University, August, 2013.

[43] Rahul Kher and Nirav Patel, "A smartphone based physiological parameters monitoring system", i-Manager's J. Embed. Sys., vol. 4, no. 4 , pp. $15-20,2016$.

[44] Rahul K., Bhaskar T., Ninad G., and Jil P., "Ambulatory ECG recording system based on ADS 1298 and STM32L431xx microcontroller", Int. J. Simul. Sys. Sci. Tech., vol. 20, no. 5, pp. 3.1-3.6, 2019

[http://dx.doi.org/10.5013/IJSSST.a.20.05.03]

[45] J. Wan, and A. A. H. Al-awlaqi, "Wearable IoT enabled real-time health monitoring system", J. Wireless Com. Network 2018, p. 298, 2018 .

[http://dx.doi.org/10.1186/s13638-018-1308-x]

[46] M.W. Woo, J. Lee, and K. Park, "A reliable IoT system for personal healthcare devices", Future Gener. Comput. Syst., vol. 78, pp. 626-640, 2018.

[http://dx.doi.org/10.1016/j.future.2017.04.004]

[47] J. Wan, and M. O'Grady, "M. li, M. Alaqi, Time-bouned activity recognition for ambient assisted living", IEEE Trans. Emerg. Top. Comput., vol. 3, no. 1, pp. 1-14, 2018.

[48] S. Hui, and W. Zhongmin, "Compressed sensing method for human activity recognition using tri-axis accelerometer on mobile phone", $J$. China Univ. Post Telecommun., vol. 24, no. 2, pp. 31-71, 2017. [http://dx.doi.org/10.1016/S1005-8885(17)60196-1]

[49] N.G. Hallfors, M. Alhawari, M. Abi Jaoude, Y. Kifle, H. Saleh, K. Liao, M. Ismail, and A.F. Isakovic, "Graphene oxide: Nylon ECG sensors for wearable IoT healthcare-nanomaterial and SOC interface", Analog Integr. Circ. Sig. Process., vol. 1, pp. 1-8, 2018. [http://dx.doi.org/10.1007/s10470-018-1116-6]

[50] L.E. Romero, P. Chatterjee, and R.L. Armentano, "An IoT approach for integration of computational intelligence and wearable sensors for Parkinson's disease diagnosis and monitoring", Health Technol. (Berl.), vol. 6, no. 3, pp. 167-172, 2016. [http://dx.doi.org/10.1007/s12553-016-0148-0]

[51] E.Z. Piraniy, F. Bulakiwala, M. Kagalwala, M. Kalolwala, and S. Raina, "Android based assistive toolkit for alzheimer", Procedia Comput. Sci., vol. 79, pp. 143-151, 2016. [http://dx.doi.org/10.1016/j.procs.2016.03.019]
[52] P. Verma, S.K. Sood, and S. Kalra, "Cloud-centric IoT based student healthcare monitoring framework", J. Ambient Intell. Humaniz. Comput., vol. 116, pp. 1-17, 2017.

[53] S. Sareen, S.K. Sood, and S.K. Gupta, "IoT-based cloud framework to control Ebola virus outbreak", J. Ambient Intell. Humaniz. Comput., vol. 9 , no. 3 , pp. 459-476, 2018. [http://dx.doi.org/10.1007/s12652-016-0427-7] [PMID: 32218876]

[54] S. Farhangdoust, G. Georgeson, J.B. Ihn, and F.K. Chang, "Kirigami auxetic structure for high efficiency power harvesting in self-powered and wireless structural health monitoring systems", Smart Mater. Struct., 2020.

[55] R. Sun, B. Zhang, L. Yang, W. Zhang, I. Farrow, F. Scarpa, and J. Rossiter, "Kirigami stretchable strain sensors with enhanced piezoelectricity induced by topological electrodes", Appl. Phys. Lett., vol. 112 , no. 25 , p. $251904,2018$.

[http://dx.doi.org/10.1063/1.5025025]

[56] S. Farhangdoust, S.M. Aghaei, M. Amirahmadi, N. Pala, and A. Mehrabi, "Mehrabi, Auxetic MEMS sensor", In: Sensors and Smart Structures Technologies for Civil, Mechanical, and Aerospace Systems, vol. 11379. International Society for Optics and Photonics, 2020, p. $113790 Z$.

[57] K. Yong, S. De, E.Y. Hsieh, J. Leem, N.R. Aluru, and S. Nam, "Kirigami-inspired strain-insensitive sensors based on atomically-thin materials", Mater. Today, vol. 34, pp. 58-65, 2019

[http://dx.doi.org/10.1016/j.mattod.2019.08.013]

[58] S. Farhangdoust, G. Georgeson, and J.B. Ihn, "MetaSub piezoelectric energy harvesting", In: Smart Structures and NDE for Industry 4.0, Smart Cities, and Energy Systems, vol. 11382. International Society for Optics and Photonics, 2020, p. 113820B. [http://dx.doi.org/10.1117/12.2559331]

[59] J.M. Kim, C. Cho, E.Y. Hsieh, and S. Nam, "Heterogeneous deformation of two-dimensional materials for emerging functionalities", J. Mater. Res., vol. 35, no. 11, pp. 1369-1385, 2020. [http://dx.doi.org/10.1557/jmr.2020.34] [PMID: 32572304]

[60] R. Sun, S.C. Carreira, Y. Chen, C. Xiang, L. Xu, B. Zhang, M. Chen, I. Farrow, F. Scarpa, and J. Rossiter, "Stretchable piezoelectric sensing systems for self-powered and wireless health monitoring", Adv. Mater. Technol., vol. 4, no. 5, p. 1900100, 2019.

[http://dx.doi.org/10.1002/admt.201900100]

[61] S. Farhangdoust, "Auxetic cantilever beam energy harvester", In: Smart Structures and NDE for Industry 4.0, Smart Cities, and Energy Systems, vol. 11382. International Society for Optics and Photonics, 2020, p. 113820.

[http://dx.doi.org/10.1117/12.2559327]

[62] H.C. Lee, E.Y. Hsieh, K. Yong, and S. Nam, "Multiaxially-stretchable kirigami-patterned mesh design for graphene sensor devices", Nano Res., pp. 1-7, 2020.

[http://dx.doi.org/10.1007/s12274-020-2662-7]

[63] "42gear, 6 different types of wearable technology you must know right now", available from: https://www.42gears.com/blog/6-wearable-technologies-you-must-kno w-right-now/

[64] "Gadgets now", available from: https://www.gadgetsnow.com/slideshows/5-features-that-every-smart watch-needs/infrared-sensor/photolist/

[65] "Docwire News, 5 new and emerging wearable medical devices", available from: https://www.docwirenews.com/docwire-pick/future-of-medicine-picks /top-5-wearable-medical-devices/

[66] "Happiest Mind, What are wearables?", available from: https://www.happiestminds.com/Insights/wearable-technology/

[67] K. Tarun, "6 key challenges of wearable product development", available from: https://medium.com/@outdesign/6-key-challenges-of-wearable-produc t-development-49717d88c684

\section{2021 Kher and Patel}

This is an open access article distributed under the terms of the Creative Commons Attribution 4.0 International Public License (CC-BY 4.0), a copy of which is available at: https://creativecommons.org/licenses/by/4.0/legalcode. This license permits unrestricted use, distribution, and reproduction in any medium, provided the original author and source are credited. 